\title{
A STUDY OF CRANIOFACIAL CONGENITAL ANOMALIES IN THE MALWA REGION (MADHYA PRADESH)
}

\author{
Seema Garg1, S. K. Wankhede2, Anil Kumar Garg 3 \\ 1 Demonstrator, Department of Anatomy, Amaltas Institute of Medical Sciences, Dewas. \\ 2 Professor, Department of Anatomy, Amaltas Institute of Medical Sciences, Dewas. \\ ${ }^{3}$ Director, Department of Plastic Surgery, Rejuvenate Plastic Surgery Center, Indore.
}

\section{ABSTRACT}

Development of foetus is a complex chain of events, millions of factors affect it. The rapid decline in the infant mortality \& morbidity in the developed countries has focused the attention of pediatricians on the problems of congenital malformations. It is impossible to know all the factors at this juncture. But so far we have come to know some factors responsible for these congenital malformations.

A study was done to detect various craniofacial congenital anomalies in Malwa region (M.P.) with the aim to know various etiological factors and to emphasize importance of early treatment to prevent disfigurement and functional defects; 120 patients with craniofacial congenital anomalies attending government and private hospitals of the Indore city during the period of $01 / 06 / 2009$ to $31 / 12 / 2010$ were taken for the study.

These patients were examined for different craniofacial congenital anomalies. A detailed history and examination was carried out to evaluate relationship of sex, religion, socioeconomic status, environmental factors, maternal age, parity, occupation of parents with various craniofacial anomalies.

We detected various craniofacial congenital anomalies ranging from cleft lip and palate, ear deformities, macrostoma, nose deformities, ptosis, facial nerve paralysis and vascular malformations. Most common anomaly was cleft lip and palate followed by haemangioma, hairy naevus, ear deformities and ptosis.

These anomalies were significantly high in children belonging to low socioeconomic group. Exposure of pregnant mothers to agricultural chemicals and smoking were other significant factors. This study also shows that incidence of cleft lip and palate was relatively high in children who were born to mothers having age less than 20 years.

\section{KEYWORDS}

Craniofacial, Congenital, Anomalies, Macrostomata, Haemangioma, Naevus, Torticollis, Hypoplasia, Ptosis, Malformation, Antenatal.

HOW TO CITE THIS ARTICLE: Garg S, Wankhede SK, Garg AK. A study of craniofacial congenital anomalies in the Malwa region (Madhya Pradesh). J. Evolution Med. Dent. Sci. 2016; 5(14):647-652, DOI: 10.14260/jemds/2016/149

\section{INTRODUCTION}

Development of fetus is a complex chain of events, millions of factors affect it. The incidence of congenital defects is 1 per 50 births, so the problem is not small and needs attention. (Ref. European Surveillance of congenital anomaly 2010) Measures should be taken to prevent and correct them. Studies carried out at different places have reported several factors affecting the incidence, viz. race, parity, maternal age, genetic pattern, nutritional status and environmental factors. Early diagnosis might help to correct some serious congenital defects at an early stage and to minimize the morbidity. It might also help to reduce the anxiety of parents, especially if the defect is a minor one. Keeping these factors in mind we have done a study.

\section{AIMS AND OBJECTIVES}

1. To detect various craniofacial congenital anomalies in Malwa region.

Financial or Other, Competing Interest: None.

Submission 01-01-2016, Peer Review 30-01-2016,

Acceptance 05-02-2016, Published 17-02-2016.

Corresponding Author:

Dr. Seema Garg,

2/1, R. S. Bhandari Marg,

Janjeer Wala Chauraha,

Indore-452003, Madhya Pradesh.

E-mail: seema@anilgarg.com

DOI: $10.14260 /$ jemds/2016/149
2. To evaluate relationship of sex, religion, socioeconomic status, environmental factors, maternal age, parity, occupation of parents to various craniofacial congenital anomalies.

3. To find out any other etiological factor.

4. To emphasize importance of early treatment to prevent disfigurement and functional defect.

\section{MATERIALS AND METHOD}

One hundred and twenty patients with craniofacial congenital anomalies attending government and private hospitals of the Indore city from $01 / 06 / 2009$ to $31 / 12 / 2010$ were taken for the study. A detailed history and examination was carried out to detect different craniofacial congenital anomalies. They were classified as per part of face involved and tabulated.

\section{OBSERVATIONS}

\begin{tabular}{|c|c|c|c|}
\hline & $\begin{array}{c}\text { Low Socio- } \\
\text { economic group }\end{array}$ & $\begin{array}{c}\text { Middle socio- } \\
\text { economic group }\end{array}$ & Total \\
\hline Urban & 18 & 30 & 48 \\
\hline Rural & 66 & 06 & 72 \\
\hline Total & $\mathbf{8 4}$ & $\mathbf{3 6}$ & $\mathbf{1 2 0}$ \\
\hline \multicolumn{3}{|c|}{ Table 1: Distribution of Study Population } \\
\hline
\end{tabular}




$\begin{gathered}\text { Distribution of cases of craniofacial congenital anomalies according to } \\
\text { part of face involved }\end{gathered}$
\begin{tabular}{|l|c|c|}
\hline Part of face involved & Number of cases & Percentage \\
\hline Lip and palate & 40 & 33.33 \\
\hline Ear deformity & 13 & 10.83 \\
\hline Nose deformity & 06 & 5 \\
\hline Eye (Ptosis) & 13 & 10.83 \\
\hline Macrostoma & 06 & 5 \\
\hline Facial Nerve Paralysis & 05 & 4.16 \\
\hline Haemangioma & 18 & 15 \\
\hline Hairy Naevus & 17 & 1.66 \\
\hline Mandible & 02 & 100 \\
\hline Total & $\mathbf{1 2 0}$ & \\
\hline
\end{tabular}

Table 2

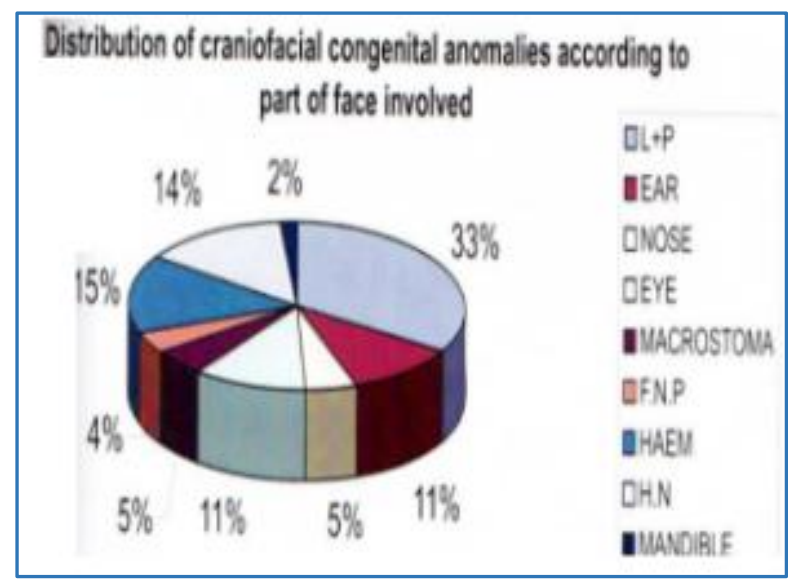

CLEFT LIP AND CLEFT PALATE

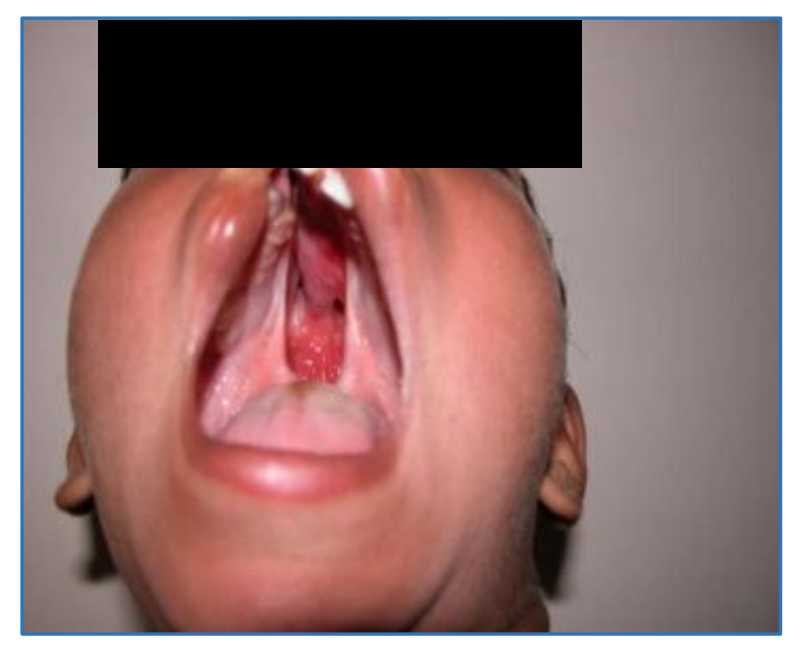

Fig. 1: Deep extended Cleft Lip and Palate

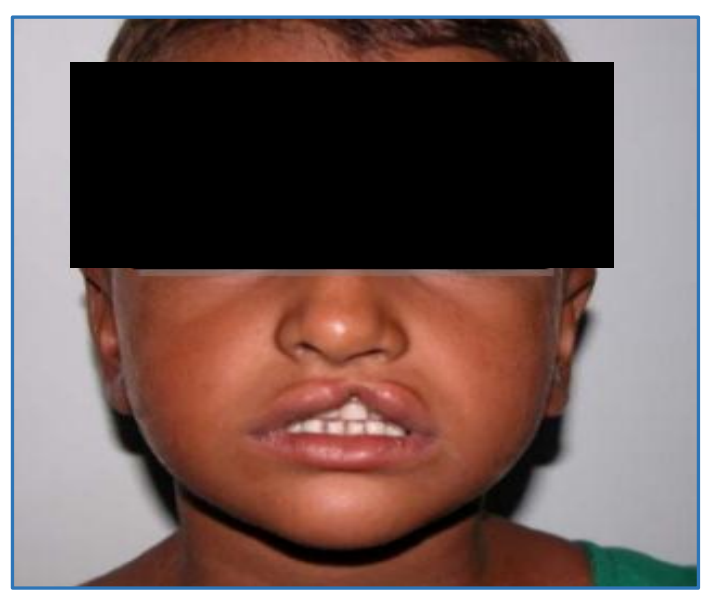

Fig. 2: Partial Cleft Lip

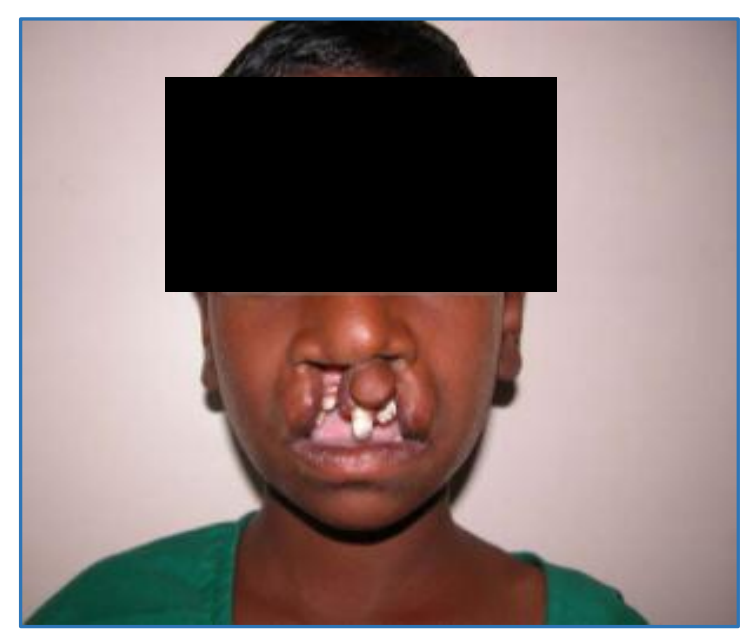

Fig. 3: Unilateral Cleft Lip extended deep 


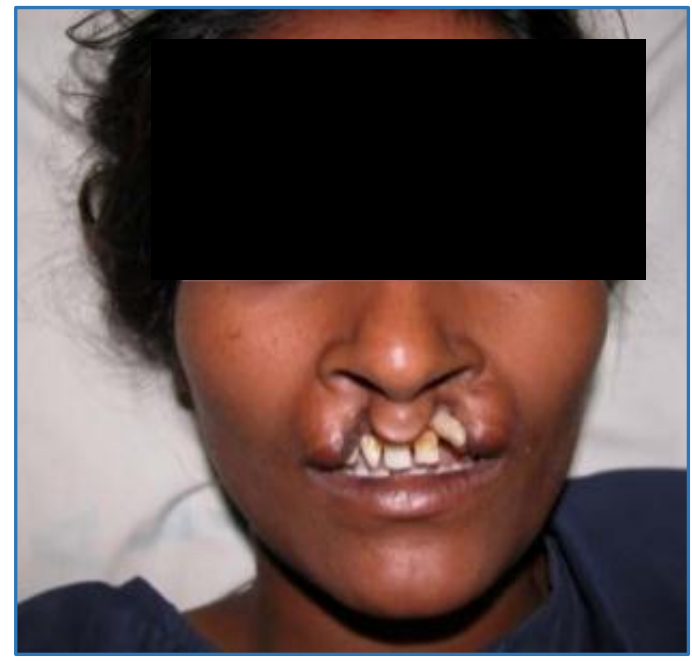

Fig. 4: Midline Cleft Lip-extended deep

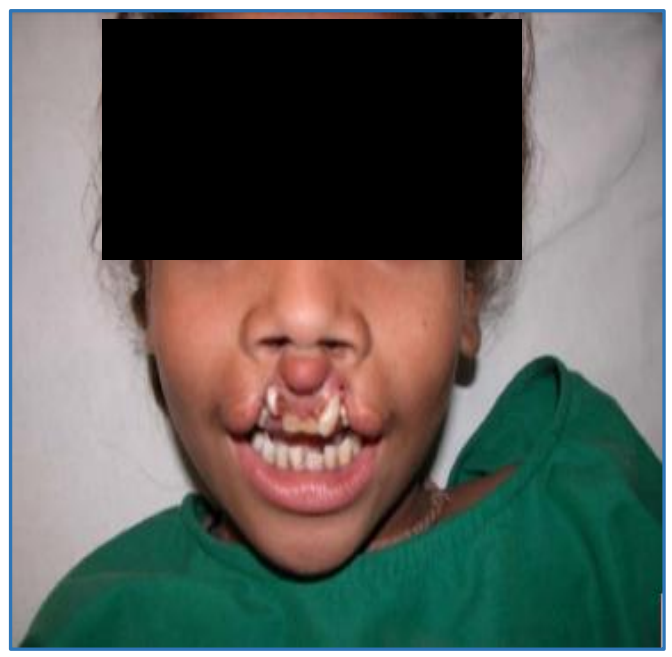

Fig. 5: Midline Cleft Lip

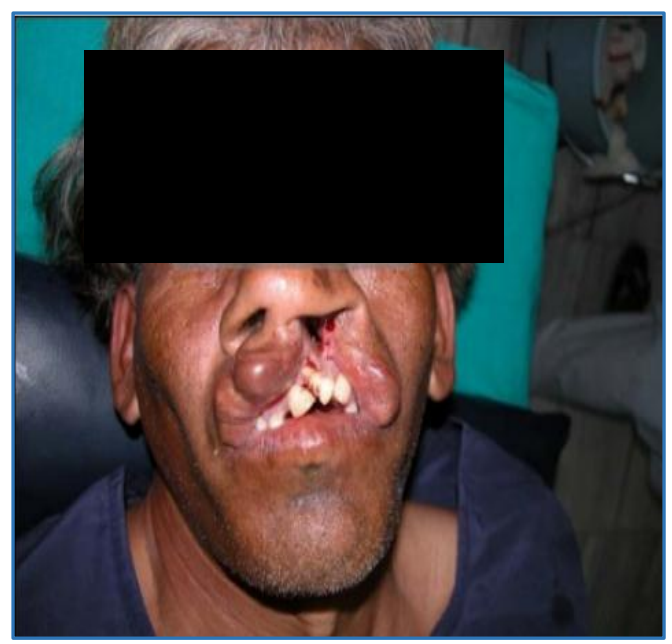

Fig. 6: Cleft Lip and Cleft Palate-unilateral deeply extended

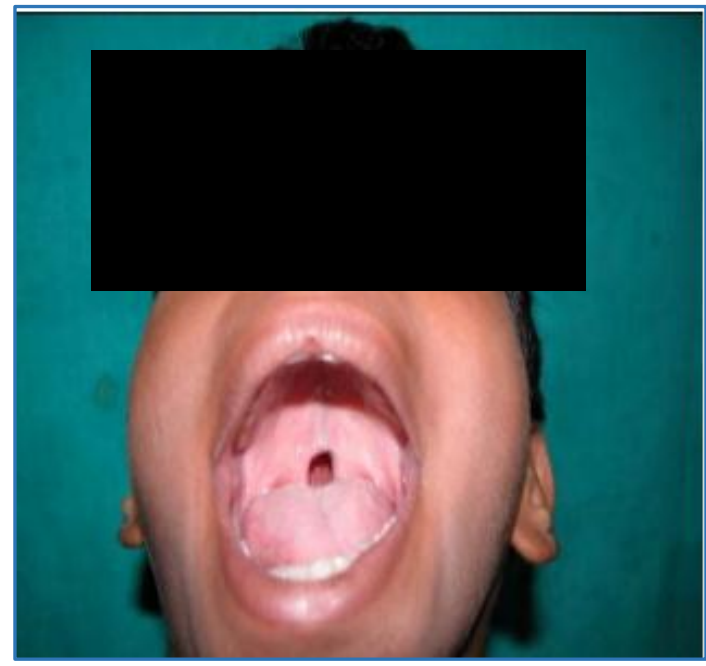

Fig. 7: A hole seen in posterior part of palate

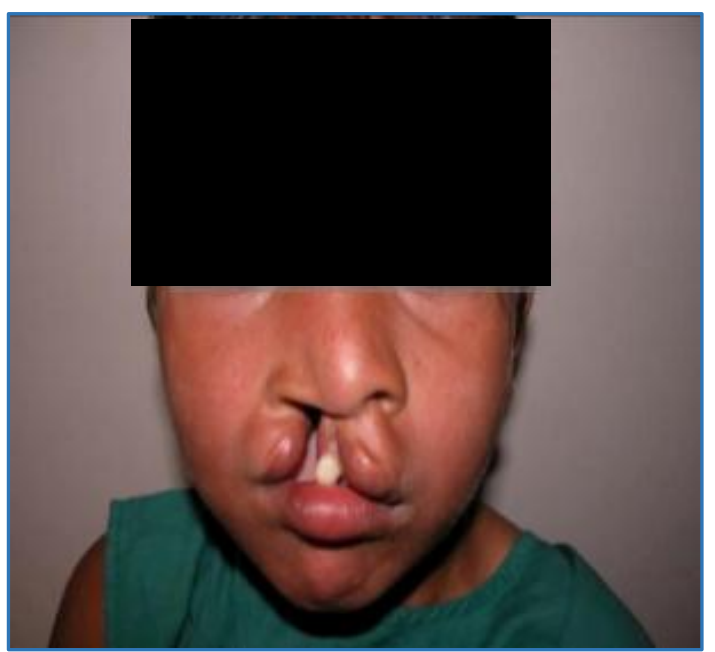

Fig. 8: Right sided Cleft Lip and Palate

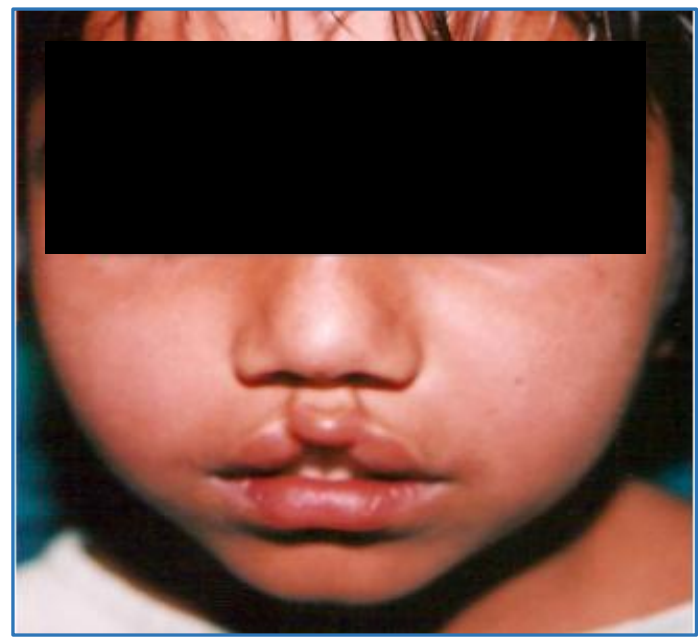

Fig. 9: A Fused type of Cleft Lip 


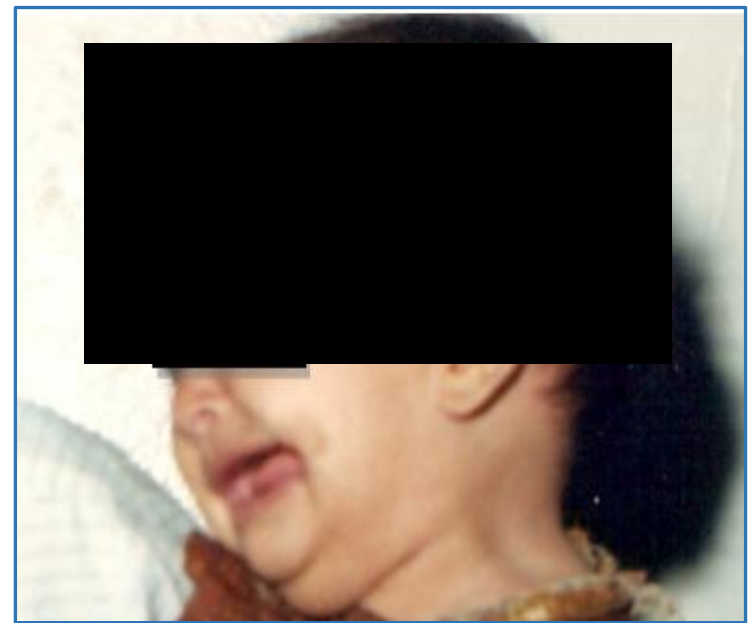

Fig. 10: Macrostoma (Lateral cleft)

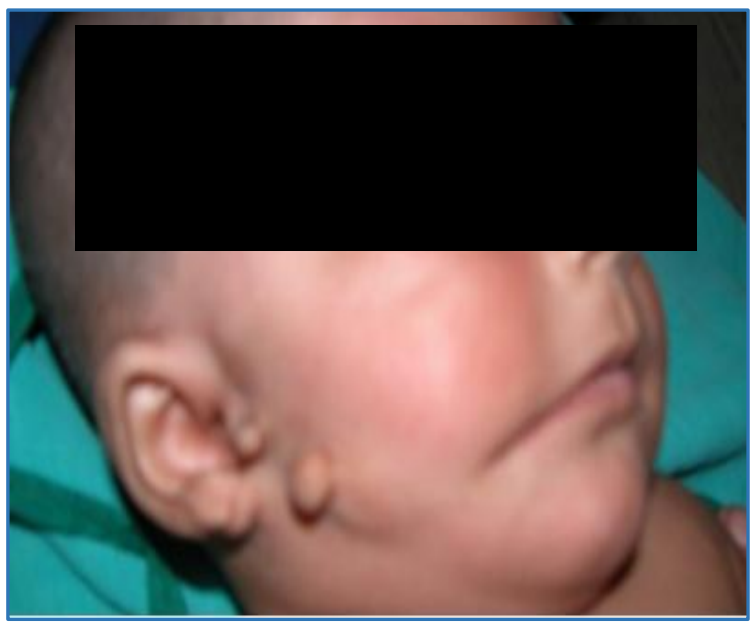

Fig. 11: Macrostoma (Lateral cleft)

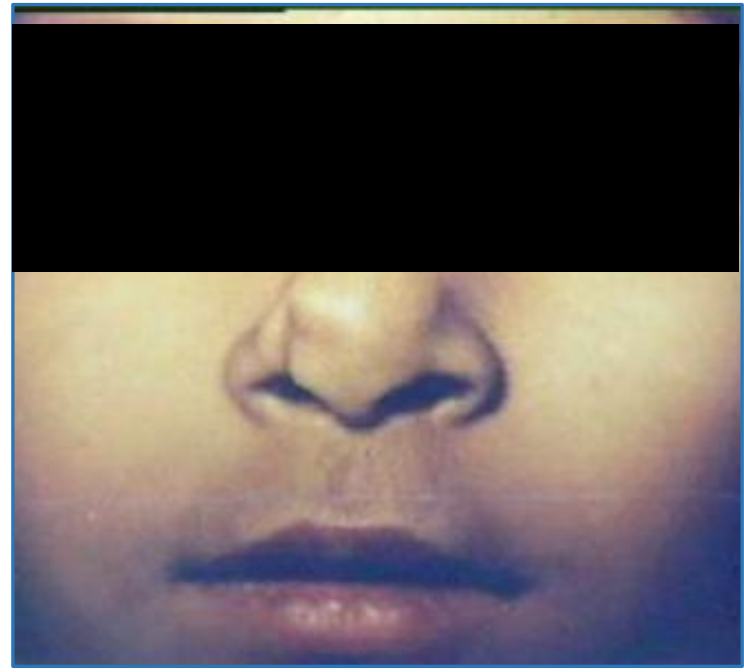

Fig. 12: Macrostomata involving right side of nose

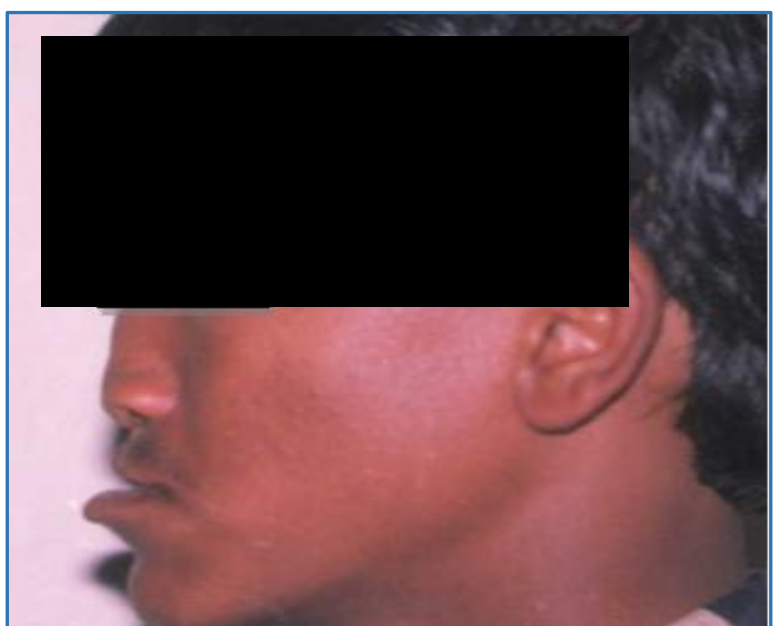

Fig. 13: Macrostomata flattening of nose and protrusion of lower lip (Lateral view)

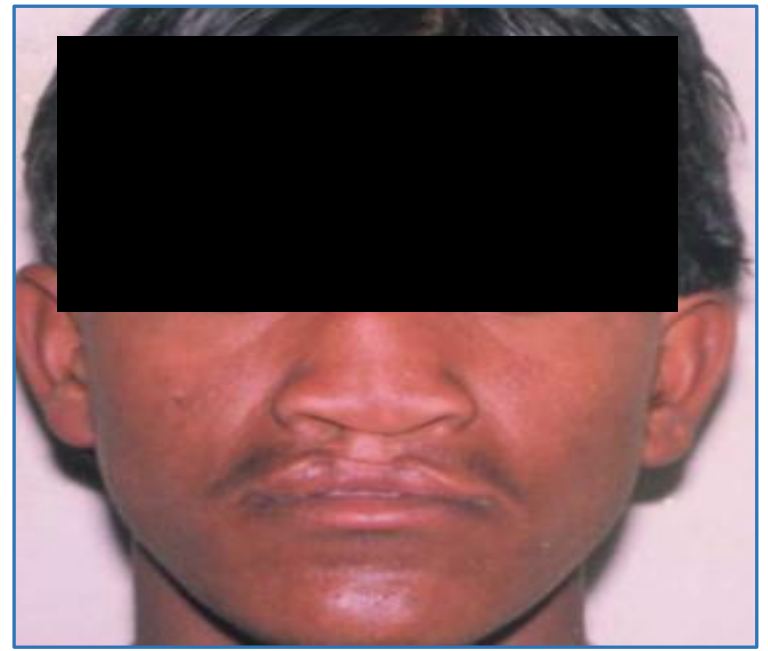

Fig. 14: Front view of Fig. 13 showing partial cleft

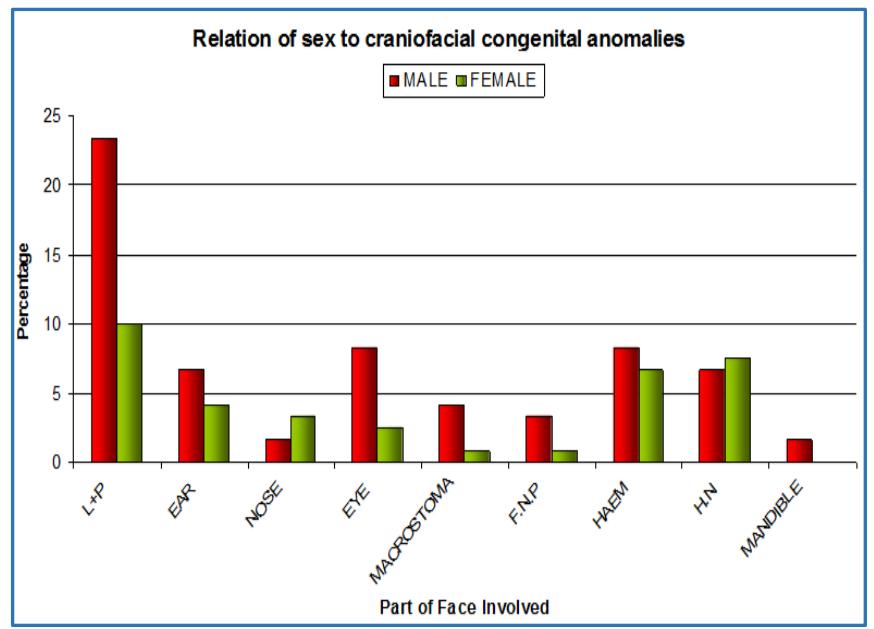




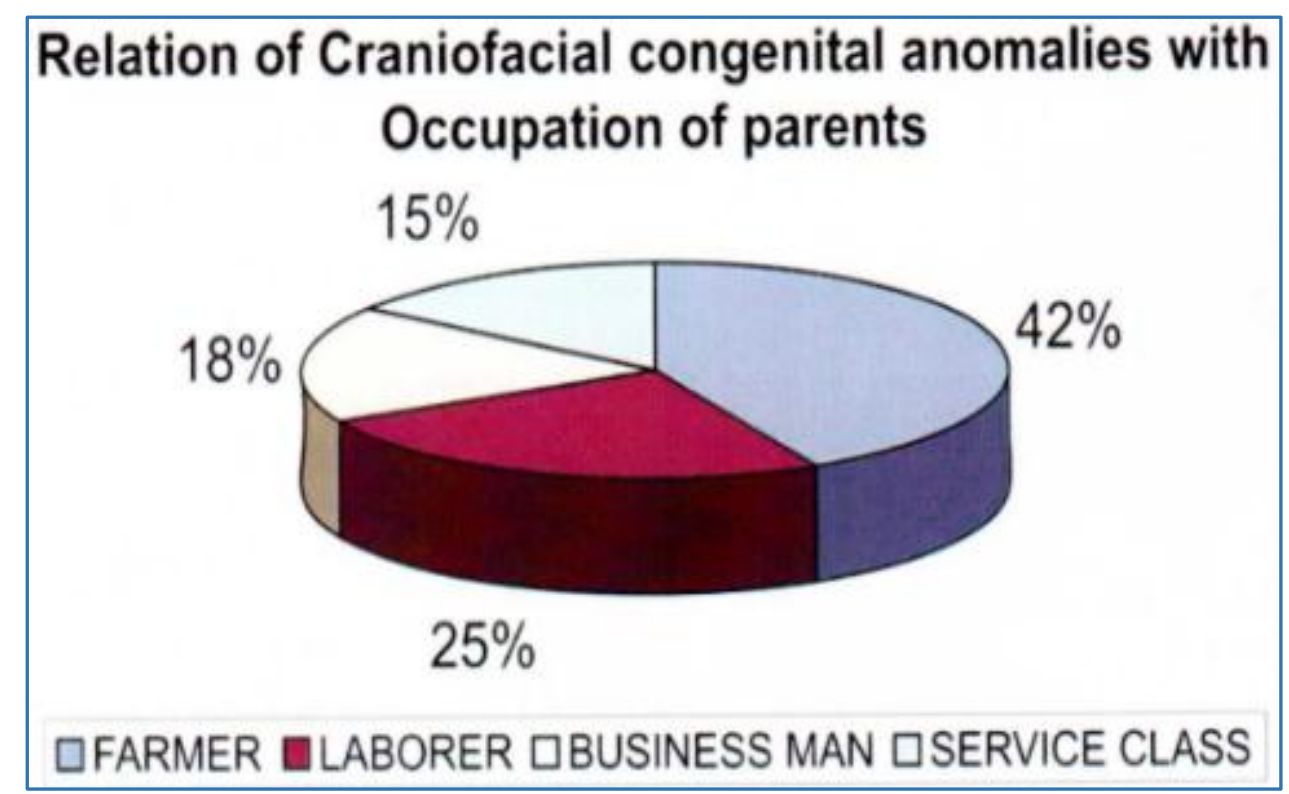

\begin{tabular}{|l|c|c|c|c|c|c|}
\hline \multicolumn{2}{|c|}{ Relation of Craniofacial congenital anomalies with maternal age } \\
\hline \multirow{2}{*}{$\begin{array}{c}\text { Part of face } \\
\text { involved }\end{array}$} & \multicolumn{5}{c|}{ Maternal age } \\
\cline { 2 - 7 } & No. & $\%$ & No. & $\%$ & No. & $\%$ \\
\hline LIP + PALATE & 22 & 18.33 & 18 & 15 & 40 & 33.33 \\
\hline EAR & 04 & 3.33 & 09 & 7.5 & 13 & 10.83 \\
NOSE & 03 & 2.5 & 03 & 2.5 & 06 & 5.0 \\
\hline EYE(Ptosis) & 05 & 4.16 & 08 & 6.66 & 13 & 10.83 \\
\hline MACROSTOMA & 02 & 1.66 & 04 & 3.33 & 06 & 5 \\
FACIAI. NERVE & 02 & 1.66 & 03 & 2.5 & 05 & 4.16 \\
\hline HAEMANGIOMA & 10 & 8.33 & 08 & 6.66 & 18 & 15 \\
\hline HAIRY NAEVUS & 06 & 5 & 11 & 9.16 & 17 & 14.16 \\
MANDIBI.E & 01 & 0.83 & 01 & 0.83 & 02 & 1.66 \\
\hline TOTAl. & 55 & 45.83 & 65 & 54.16 & 120 & 100 \\
\hline
\end{tabular}

Table 3

\begin{tabular}{|} 
Relation of Craniofacial congenital anomalies with maternal parity \\
\begin{tabular}{|l|c|c|c|c|c|c|}
\hline \multirow{2}{*}{$\begin{array}{c}\text { Part of face } \\
\text { involved }\end{array}$} & \multicolumn{2}{c|}{ parity } \\
\cline { 2 - 8 } & \multicolumn{2}{|c|}{ Primi } & \multicolumn{2}{c|}{ Multi $(>1)$} & \multicolumn{2}{c|}{ Total } \\
\cline { 2 - 8 } & No. & $\%$ & No. & $\%$ & No. & $\%$ \\
\hline L.P + PALATE & 05 & 4.16 & 35 & 29.16 & 40 & 33.33 \\
\hline EAR & 05 & 4.16 & 08 & 6.66 & 13 & 10.83 \\
\hline NOSE & 02 & 1.66 & 04 & 3.33 & 06 & 5.0 \\
\hline EYE(Ptosis) & 02 & 1.66 & 11 & 9.16 & 13 & 10.83 \\
\hline MACROSIOMA & 01 & 0.83 & 05 & 4.16 & 06 & 5 \\
\hline FACIAL NERVE & 01 & 0.83 & 04 & 3.33 & 05 & 4.16 \\
\hline HAEMANGIOMA & 10 & 8.33 & 08 & 6.66 & 18 & 15 \\
\hline ILAIRY NAEVUS & 06 & 5 & 11 & 9.16 & 17 & 14.16 \\
\hline MANDIBLE & 01 & 0.83 & 01 & 0.83 & 02 & 1.66 \\
\hline TOTAL & 33 & 27.5 & 87 & 72.5 & 120 & 100 \\
\hline
\end{tabular}
\end{tabular}




\section{CONCLUSION}

Most common anomaly was cleft lip and palate followed by haemangioma, hairy nevus, ear deformities and ptosis.

\section{RESULTS}

1. These anomalies were significantly high in children belonging to low socioeconomic group.

2. Exposure of pregnant mothers to agricultural chemicals and smoking were other significant factors.

3. This study also shows that incidence of cleft lip and palate was relatively high in children who were born to mothers having age less than 20 years.

4. This study throws light on certain definite preventive approaches to the problems of craniofacial congenital anomalies.(1)

5. The importance of proper antenatal care with special attention to avoid exposure to certain agricultural chemicals, smoke of tobacco (Either active or passive smoking) should be taken into consideration in awareness programs. (2)

6. Child birth should be avoided in too early (Age $<20$ ) or too late (After 40 years) an age.(3)

7. National programs for maternal and child health care should also focus on reducing the incidences of craniofacial congenital anomalies.

8. There is a need to establish centers capable of counseling and providing antenatal diagnosis of anomalies at a peripheral level.(2)

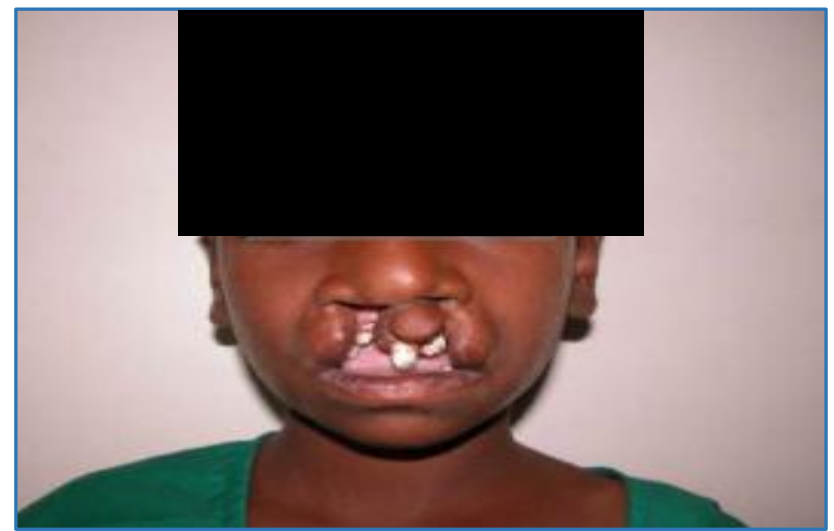

Fig. 15: Cleft Lip

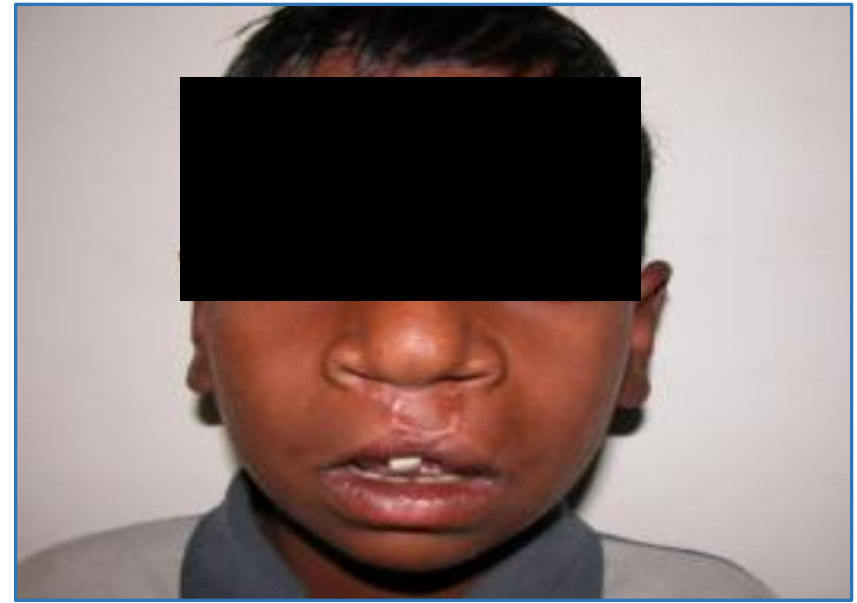

Fig. 16: Corrected After Surgery

\section{SUGGESTIONS}

We want to emphasize upon the fact that most of the facial congenital anomalies are treatable by surgical correction and cosmetically and functionally good results can be achieved.

By spreading awareness of this fact, psychological trauma of parents can be reduced to a great extent and also the financial burden of the family and the society at large.

\section{REFERENCES}

1. Edwards TC, Patrick DL, Topolski TD, et al. Approaches to craniofacial-specific quality of life assessment in adolescents. Cleft Palate Craniofac J 2005;42:19-24.

2. Hunt O, Burden D, Hepper P, et al. The psychological effects of cleft lip and palate: a systematic review. Eur J Orthod 2005;27:274-285.

3. Slavkin HC. The surgeon general's report and specialneeds patients: a framework for action for children and their caregivers. Spec Care Dentist 2001;21:88-94. 